\title{
Synergistic fungicidal activities of polymyxin B and ionophores, and their dependence on direct disruptive action of polymyxin $B$ on fungal vacuole
}

\begin{abstract}
Akira Ogita ${ }^{1}$, Yukiko Konishi², Baiyinlang Borjihan ${ }^{2}$, Ken-ichi Fujita ${ }^{2}$ and Toshio Tanaka ${ }^{2}$
Polymyxin B (PMB) acts selectively on Gram-negative bacteria by electrostatic and hydrophobic interactions with anionic cell envelope components such as phospholipids and lipopolysaccharides. In this study, PMB was shown to exhibit marked fungicidal activity against yeasts and filamentous fungi in combination with ionophores such as salinomycin (SAM) and monensin (MON), which can selectively interact with monovalent cations. $\mathrm{Ca}^{2+}$-selective ionophores, $\mathrm{A23187}$ and ionomycin, were absolutely ineffective in enhancing the fungicidal activity of PMB. SAM and MON increased the rate of cellular uptake of PMB possibly in favor of its intracellular action on the organelle. PMB could indeed directly disrupt the spherical membraneenclosed architecture of the isolated vacuoles equally in the absence and presence of the ionophores. The loss of energy barrier for transmembrane transport of monovalent cations is considered to be a cause of enhanced incorporation of larger cationic compounds such as PMB across fungal plasma membrane.
\end{abstract}

The Journal of Antibiotics (2009) 62, 81-87; doi:10.1038/ja.2008.13; published online 9 January 2009

Keywords: Aspergillus niger; Candida albicans; ionophores; polymyxin B; Saccharomyces cerevisiae; vacuole

\section{INTRODUCTION}

Polymyxin B (PMB; Figure 1), a complex antibacterial antibiotic produced by Bacillus polymyxa, consists of a cyclic heptapeptide moiety, a straight tripeptide side chain, and a fatty acid attached to the $\mathrm{N}$ terminus of the side chain. ${ }^{1}$ The molecule carries five positively charged residues of diaminobutyric acid. Owing to its charge and amphiphilicity, $\mathrm{PMB}$ may be prevented from penetration into the outer membrane of Gram-negative bacteria. However, PMB binds to lipopolysaccharide so as to form a complex and increases the permeability of the outer membrane to a variety of molecules, including also its own uptake. ${ }^{2}$ In addition, when yeast cells are incubated with PMB at the concentration too low to affect their growth in the presence of various antibiotics, for instance tetracycline or miconazole, PMB increases the permeability of plasma membrane to each antibiotic and their combinations can induce cell death. ${ }^{3-5}$ In our recent study, $\mathrm{PMB}$ was found to cause vacuolar membrane-disruptive damage in Saccharomyces cerevisiae cells when this bactericidal antibiotic is added alone at a high concentration and also at a non-lethal concentration in combination with allicin (Figure 1), an allyl sulfur compound from garlic. $^{6}$

The vacuole-disruptive damage in fungi was first observed when S. cerevisiae cells were treated with a polyol macrolide antibiotic niphimycin $(\mathrm{NM}) .^{7,8} \mathrm{NM}$ consists of two major structural domains such as polyol lactone ring and alkylguanidinium chain attached to the ring. These molecular domains were suggested to interact with each other for exhibition of the vacuole-targeting fungicidal activity. ${ }^{9}$ This was later supported by a synergistic cooperation between the synthetic analog of this alkyl side chain and a polyene macrolide antibiotic amphotericin $\mathrm{B}(\mathrm{AmB})$ as a substitute for the lactone ring of $\mathrm{NM}^{7}$ In another experiment using S. cerevisiae cells, $\mathrm{AmB}$ was shown to exhibit a vacuole-targeting fungicidal activity at a high concentration under hypoosmotic condition, and the AmBinduced intracellular lethal event was also markedly enhanced in the presence allicin. ${ }^{10}$ We are focusing our attention to the enhancement effect of allicin and consider its inhibitory effect on a mechanism of ergosterol trafficking from the plasma membrane to the vacuolar membrane to be a cause of enhancement of the vacuole-targeting activity of AmB (A. Ogita et al., unpublished results). Allicin could alternatively facilitate the vacuole-targeting fungicidal activity of PMB because of its role as an enhancer of cellular uptake of this cationic cyclic peptide. ${ }^{6}$ These findings highly suggest a possibility to apply PMB for antifungal chemotherapy if its vacuole-targeting activity can be enhanced with a compound that is more suitable for clinical use than allicin.

${ }^{1}$ Research Center for Urban Health and Sports, Osaka City University, Sumiyoshi-ku, Osaka, Japan and ${ }^{2}$ Department of Biology and Geosciences, Graduate School of Science, Osaka City University, Sumiyoshi-ku, Osaka, Japan

Correspondence: Dr T Tanaka, Department of Biology and Geosciences, Graduate School of Science, Osaka City University, 3-3-138 Sugimoto, Sumiyoshi-ku, Osaka 558-8585, Japan.

E-mail: tanakato@sci.osaka-cu.ac.jp

Received 19 November 2008; accepted 19 November 2008; published online 9 January 2009 


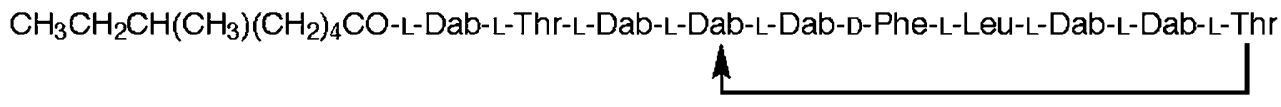

Polymyxin B (PMB)

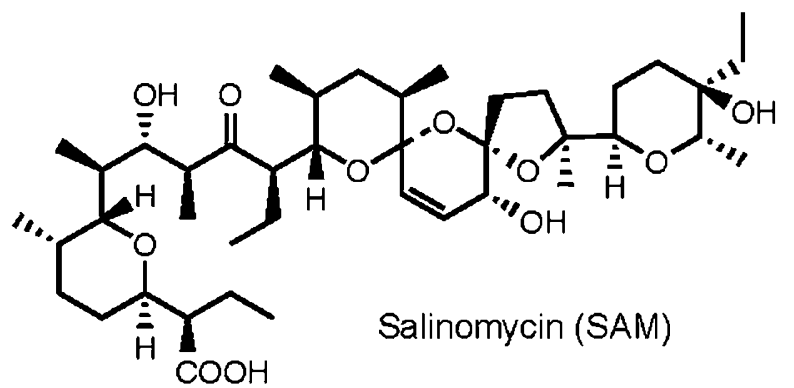

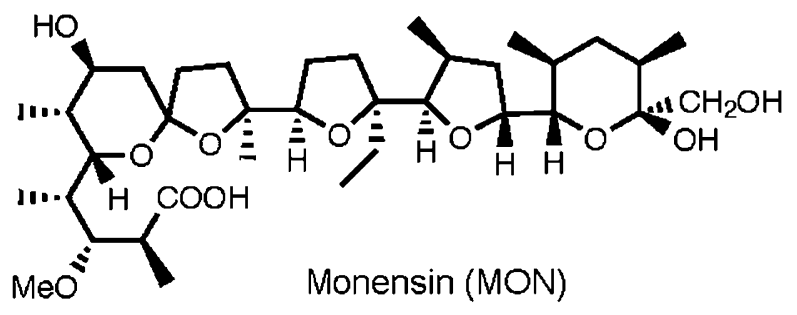<smiles>C=CCS(=O)CC=C</smiles>

Allicin

Figure 1 Structures of PMB, SAM, MON, and allicin. MON, monensin; PMB, polymyxin B; SAM, salinomycin.

Salinomycin (SAM) is a fermentation product of Streptomyces albus, whereas monensin (MON) is from Streptomyces cinnamonensis. ${ }^{11}$ These compounds belong to monovalent carboxylic ionophorous polyether antibiotics that interfere with the plasma membrane ion transport system (Figure 1). Ionophores generally lower the energy barrier necessary for the transmembrane transport of ions and catalyze an electroneutral cation-proton exchange across the barrier. Consequently, they abolish the gradients of $\mathrm{K}^{+}, \mathrm{Na}^{+}, \mathrm{Ca}^{2+}$, and $\mathrm{Mg}^{2+}$ depending on the affinity to each of these metal ions. ${ }^{12}$ SAM transports $\mathrm{K}^{+}$more efficiently than $\mathrm{Na}^{+}$, whereas MON transports $\mathrm{Na}^{+}$more efficiently than $\mathrm{K}^{+} .{ }^{13}$ The cell walls of most Gram-negative bacteria do not permit the penetration of hydrophobic compounds with molecular weights of $\geqslant 600$, and thus render the bacterial cells mostly resistant to the action of ionophores. ${ }^{12}$ Instead, SAM and MON can effectively inhibit the growth of Gram-positive bacteria, and have been used as antimicrobial growth promoters in animal feed especially for bovine and swine. ${ }^{14}$

In this study, we found a synergistic relationship between PMB and each of these ionophores in the growth inhibition of pathogenic fungal strains such as Candida albicans and Aspergillus niger in addition to S. cerevisiae. PMB could indeed disintegrate the vacuolar membrane of both $S$. cerevisiae and A. niger cells at a non-lethal concentration in combination with either SAM or MON, and was found to cause disruptive damages directly on the vacuoles isolated from $S$. cerevisiae cells by its own action. Our study suggests that the plasma membrane barrier against monovalent cations also functions for preventing incorporation of positively charged larger compounds such as PMB into cells.

\section{MATERIALS AND METHODS}

Measurement of cell growth and viability

MICs of PMB, SAM, and MON were determined against Escherichia coli IFO 3545, Bacillus subtilis IFO 3007, S. cerevisiae W303-1A, C. albicans IFO 1061, A. niger ATCC 6275, and Mucor mucedo IFO 7684 according to our earlier described method. ${ }^{6,7}$ The effects of PMB and these ionophores on cell viability were also examined against $S$. cerevisiae by counting viable cell numbers as colony-forming units.

\section{Assay of plasma membrane phospholipid peroxidation}

The extent of plasma membrane phospholipid peroxidation was examined using a florescence probe, diphenyl-1-pyrenylphosphine, as reported earlier. ${ }^{15,16}$ The fluorescence intensities of the cell suspensions were measured using an FP1520 S fluorescence detector (JASCO, Tokyo, Japan), in which the wavelengths of excitation and emission were adjusted at $351 \mathrm{~nm}$ and at $380 \mathrm{~nm}$, respectively. The arbitrary units were based directly on fluorescence intensity.

\section{Vacuole isolation}

Vacuoles were isolated from S. cerevisiae cells according to the earlier described methods ${ }^{17-19}$ with the following modifications: cells were grown overnight in YPD medium, harvested by centrifugation, and suspended in the spheroplasting buffer (50 mM Tris-HCl, $\mathrm{pH} 7.5 ; 1.0 \mathrm{M}$ sorbitol; $10 \mathrm{~mm}$ sodium azide; $0.5 \%$ 2-mercaptoethanol) at the density of $1 \times 10^{9}$ cells $/ \mathrm{ml}$, and the cell suspension was incubated at $30^{\circ} \mathrm{C}$ for $30 \mathrm{~min}$. After the addition of Yeast Lytic Enzyme at $5.0 \mathrm{mg} \mathrm{ml}^{-1}$ in the cell suspension, cells were converted to spheroplasts by incubation at $30^{\circ} \mathrm{C}$ for $60 \mathrm{~min}$ with gentle agitation. The spheroplasts were collected by centrifugation, carefully washed with the vacuole-isolating buffer ( $10 \mathrm{~mm}$ sodium citrate, $\mathrm{pH} 6.8 ; 0.6 \mathrm{M}$ sorbitol), and suspended in the buffer at $5 \times 10^{9}$ cells $/ \mathrm{ml}$. Further procedures were all carried out on ice. The spheroplasts were homogenized by 20 strokes in a Dounce homogenizer. The homogenate $(15 \mathrm{ml})$ was transferred to an centrifugation tube, gently overlaid with $10 \mathrm{ml}$ of 
the vacuole-isolating buffer containing $7.0 \%$ Ficoll and $10 \mathrm{ml}$ of the buffer containing $8.0 \%$ Ficoll on the top, and centrifuged $(3000 \mathrm{~g})$ at $4{ }^{\circ} \mathrm{C}$ for $30 \mathrm{~min}$. Vacuoles were collected from the 0 to $7.0 \%$ Ficoll interface.

\section{Vacuole staining}

Vacuoles were visualized according to the method of Vida and $\mathrm{Emr}^{20}$ as follows: S. cerevisiae cells were grown overnight in YPD medium at $30^{\circ} \mathrm{C}$ and harvested by centrifugation. A. niger cells were pre-incubated for $24 \mathrm{~h}$ in malt extract medium at $30^{\circ} \mathrm{C}$ with shaking and harvested by filtration. These fungal cells were washed with fresh medium and suspended in each of the above media to obtain a density of $1 \times 10^{7}$ cells $/ \mathrm{ml}$ (S. cerevisiae) or to obtain the original mycelial concentration (A. niger). The fluorescent probe FM4-64 was added to the cell suspensions at a final concentration of $5.0 \mu \mathrm{m}$. Cells were then incubated with shaking at $30^{\circ} \mathrm{C}$ for $30 \mathrm{~min}$, and then harvested and washed again with the fresh medium. Cells were finally suspended in the fresh medium to obtain a density of $1 \times 10^{7}$ cells $/ \mathrm{ml}$ (S. cerevisiae) or to obtain the original mycelial concentration (A. niger). These cell suspensions were shaken in the absence and the presence of each compound at $30^{\circ} \mathrm{C}$ for $120 \mathrm{~min}$. Cells were then observed under the bright field and fluorescence microscope with excitation at $480 \mathrm{~nm}$ and emission at $530 \mathrm{~nm}$.

\section{HPLC analysis of PMB}

S. cerevisiae cells were grown overnight in YPD medium and harvested by centrifugation. Cells were washed with YPD medium and suspended in the medium to obtain a density of $1 \times 10^{8}$ cells $/ \mathrm{ml}$. The cell suspensions were then shaken with PMB in the absence and the presence of each ionophore at $30^{\circ} \mathrm{C}$ for $120 \mathrm{~min}$. The supernatants obtained after cell removal by centrifugation were assayed for PMB content by HPLC using a reverse-phase column (4.7 by $250 \mathrm{~mm}$, YMC-Pack ODS-AM, YMC Inc., Wilmington, NC, USA). The chromatographic solvents were $0.1 \% \quad(\mathrm{v} / \mathrm{v})$ trifluoroacetic acid in water (solvent A) and $0.075 \%(\mathrm{v} / \mathrm{v})$ trifluoroacetic acid in $\mathrm{CH}_{3} \mathrm{CN}$ (solvent B). A linear gradient was achieved from 10 to $80 \%$ of solvent B in $20 \mathrm{~min}$ at a flow rate of $1.0 \mathrm{ml} \mathrm{min}^{-1}$ and the absorbance was monitored at $210 \mathrm{~nm}$

\section{Chemicals}

PMB sulfate, SAM sodium salt, and ionomycin were purchased from Wako Pure Chemical Industries (Osaka, Japan). MON sodium salt and A23187 were obtained from Sigma Aldrich (St Louis, MO, USA). The fluorescent probe FM4-64 and diphenyl-1-pyrenylphosphine were products of Molecular Probe (Eugene, OR, USA) and Dojindo (Kumamoto, Japan), respectively. Ficoll 400 was from Alfa Aesar (Ward Hill, MA, USA), and Yeast Lytic Enzyme was from ICN Biomedicals (Aurora, OH, USA). The other chemicals used were of analytical reagent grade.

\section{RESULTS AND DISCUSSION}

\section{Synergy between PMB and ionophores}

PMB has been re-evaluated for its clinical use because of the lower toxicities than those reported earlier. ${ }^{21}$ This cyclic peptide could also be valuable as an antifungal antibiotic when fungal cells are made susceptible to its vacuole-targeting activity with the aid of another agent such as allicin. In our screening experiment, SAM and MON were selected as such agents that can amplify the growth inhibitory activity of PMB on $S$. cerevisiae cells among a number of antibiotics and drugs. The combination effects of PMB and either SAM or MON were then examined against bacteria, yeasts, and filamentous fungi by using the checkerboard technique. As shown in Figure 2a, PMB exhibited a potent growth inhibitory activity on E. coli, a Gramnegative bacterium, at $3.13 \mu \mathrm{g} \mathrm{ml}^{-1}$, and the MIC remained unchanged with increasing concentration of SAM or MON up to $400 \mu \mathrm{g} \mathrm{ml}^{-1}$. On the contrary to the fact, these ionophores were equally effective in inhibiting the growth of $B$. subtilis, a Gram-positive bacterium, at $0.78 \mu \mathrm{g} \mathrm{ml}^{-1}$, whereas their MICs were kept unchanged with increasing concentration of PMB (Figure 2b). Unlike the case with these bacterial strains, PMB exhibited a growth inhibitory activity on $S$. cerevisiae at a quite high concentration of $200 \mu \mathrm{g} \mathrm{ml}^{-1}$, but the MIC drastically decreased to 3.13 and $12.5 \mu \mathrm{g} \mathrm{ml}^{-1}$ with increasing
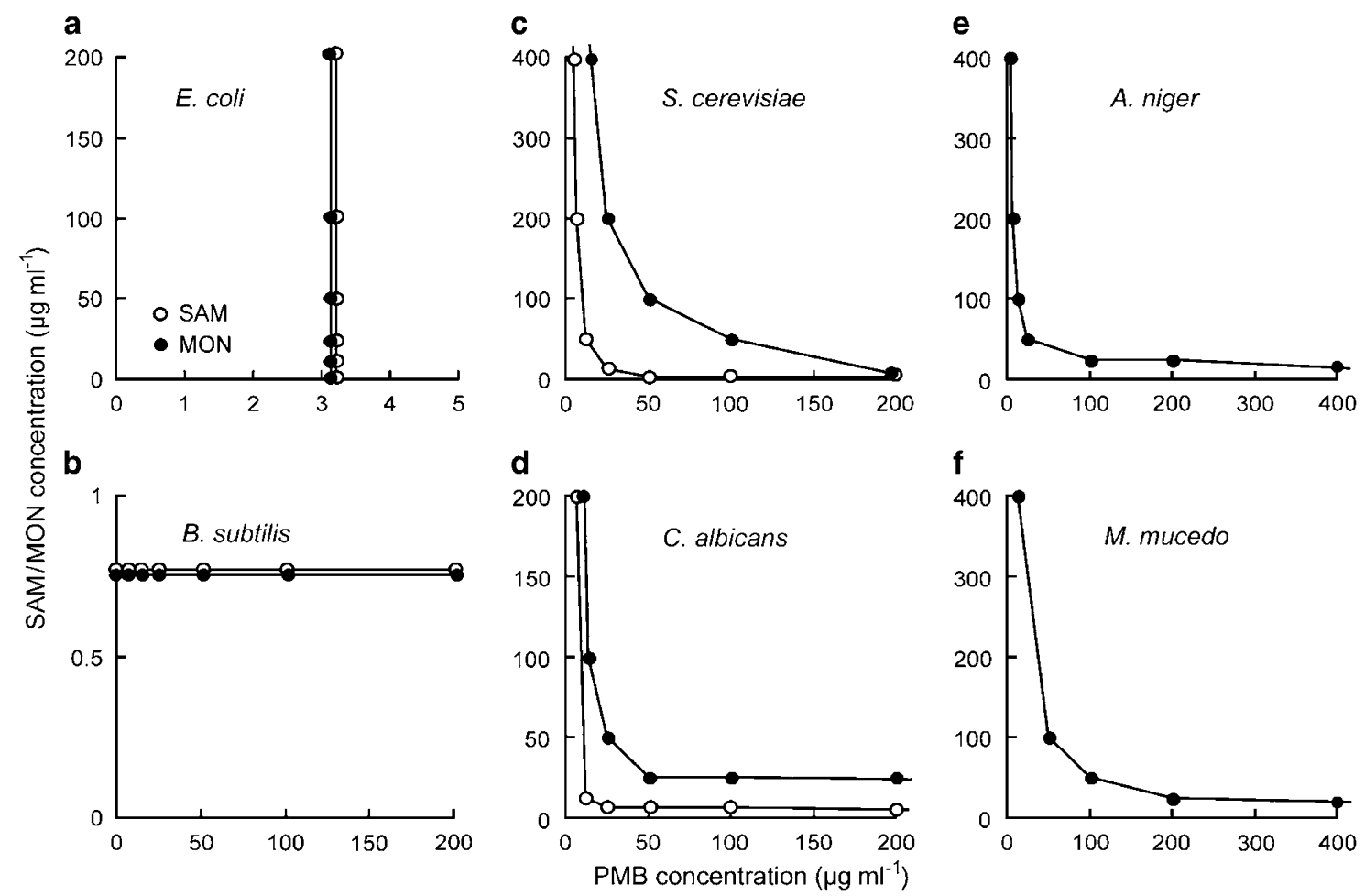

Figure 2 Isobolograms showing synergy of PMB and each of SAM and MON. Each point represents a combination of the MICs of PMB and either SAM (O) or MON (•) against Escherichia coli, Bacillus subtilis, Saccharomyces cerevisiae, Candida albicans, Aspergillus niger, and Mucor mucedo. 
concentrations of SAM and MON, respectively, up to $400 \mu \mathrm{g} \mathrm{ml}^{-1}$ (Figure 2c).

Such synergistic relationships were more markedly observed against C. albicans, though this pathogenic yeast was less sensitive to PMB than S. cerevisiae (Figure 2d). SAM was superior to MON as a counterpart of $\mathrm{PMB}$ at least in inhibiting the growth of these yeast strains, but this $\mathrm{K}^{+}$ionophore was absolutely ineffective in inhibiting the growth of filamentous fungi such as $M$. mucedo and $A$. niger at $400 \mu \mathrm{g} \mathrm{ml}^{-1}$ even in combination with $\mathrm{PMB}$ at $400 \mu \mathrm{g} \mathrm{ml}^{-1}$. On the other hand, MON could render cells of these filamentous fungi sensitive to $\mathrm{PMB}$, suggesting the dependence of their elevated sensitivities to a type of ionophore, which is characterized by more increased selectivity toward $\mathrm{Na}^{+}$than $\mathrm{K}^{+}$(Figures $2 \mathrm{e}$ and $\mathrm{f}$ ). It was therefore confirmed whether the fungicidal activity of PMB could be enhanced by two different types of ionophore, A23187 and ionomycin, which are selective for divalent cations such as $\mathrm{Ca}^{2+}$ (refs 22, 23). The MIC of PMB against $S$. cerevisiae remained at a constant level of $200 \mu \mathrm{g} \mathrm{ml}^{-1}$ equally in the absence and the presence of each $\mathrm{Ca}^{2+}$ ionophore. These results highly supported the dependence of PMBmediated fungal growth inhibition on the plasma membrane function involved in the permeability to monovalent cations.

The mode of growth inhibition by PMB was examined using $S$. cerevisiae cells in the absence and the presence of either SAM or MON by means of the colony-counting method. These ionophores scarcely caused lethal effects on cells of eukaryotic microbial strains used in this study including $S$. cerevisiae. On the other hand, the yeast cell growth was partly repressed in the presence of SAM at $50 \mu \mathrm{g} \mathrm{ml}^{-1}$, but not all affected in the presence of MON at the same concentration (data not shown). As shown in Figure 3, the yeast cells were mostly viable upon PMB treatment at $100 \mu \mathrm{g} \mathrm{ml}^{-1}$, but were subjected to the lethal effect of this antibiotic alone at $200 \mu \mathrm{g} \mathrm{ml}^{-1}$ in a time-dependent manner. In the presence of $50 \mu \mathrm{g} \mathrm{ml}^{-1}$ SAM, PMB exhibited the lethal effect at $50 \mu \mathrm{g} \mathrm{ml}^{-1}$ and could reduce the viable cell number to $10 \%$ of the original level at $\sim 3 \mathrm{~h}$ incubation at $100 \mu \mathrm{g} \mathrm{ml}^{-1}$. MON could similarly render the yeast cells susceptible to the lethal effect of PMB in a dose-dependent manner. In these experiments, PMB, SAM, and MON were required at the higher concentrations than expected from their MIC values (see Figure 2), as the cell densities were adjusted to the higher levels such as $10^{7} \mathrm{ml}^{-1}$ essential for conducting the following physiological experiments.

\section{Effects of SAM and MON on PMB-induced vacuole morphological} change

PMB causes vacuolar membrane-disruptive damage in S. cerevisiae cells when this bactericidal antibiotic is added alone at a high concentration and also at a non-lethal concentration in combination with allicin. ${ }^{6}$ We thus attempted to examine whether SAM or MON can enhance the vacuole-disruptive activity of PMB by microscopic
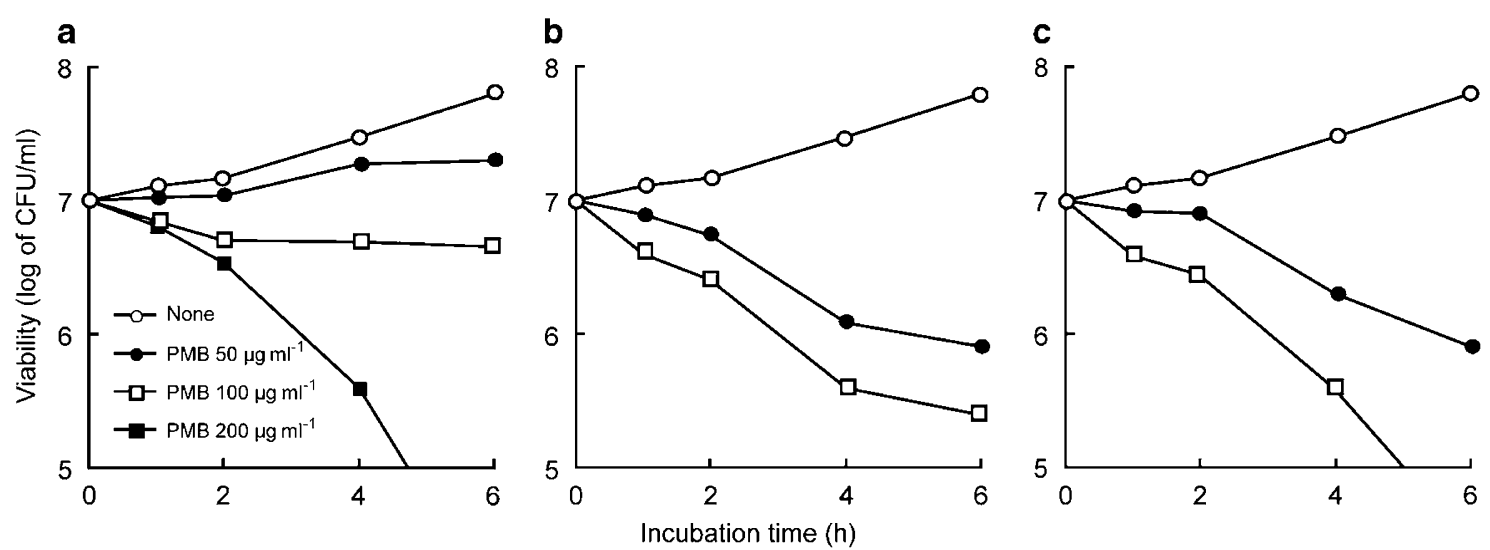

Figure 3 Growth inhibitory effects of PMB on Saccharomyces cerevisiae cells in the absence and the presence of either SAM or MON. (a) Cells (10 $\mathrm{ml}^{-1}$ ) were incubated in YPD medium with PMB at $0(O), 50(\bullet), 100(\square)$, and $200 \mu \mathrm{gml}^{-1}(\mathbf{\square})$. (b) Cells were incubated in YPD medium containing

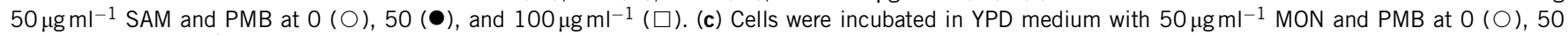
$(\bullet)$, and $100 \mu \mathrm{gll}^{-1}(\square)$.

a

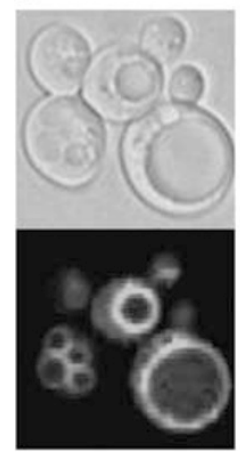

b

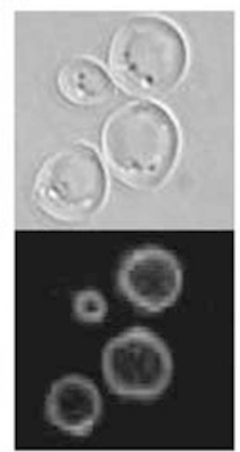

c

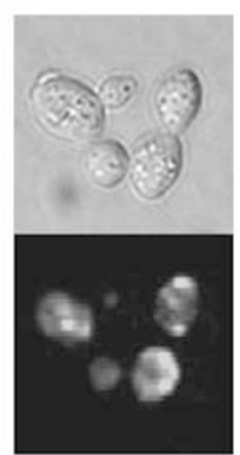

d

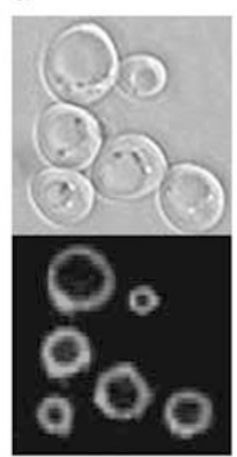

e

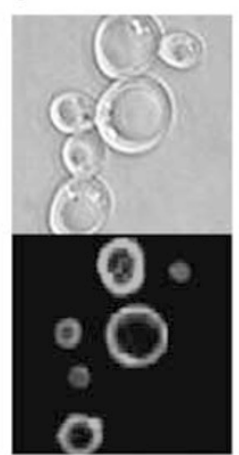

f

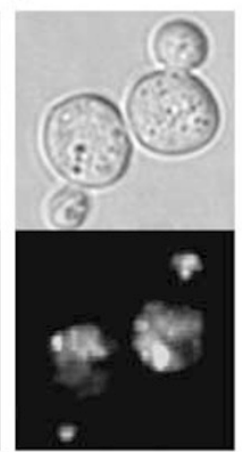

g

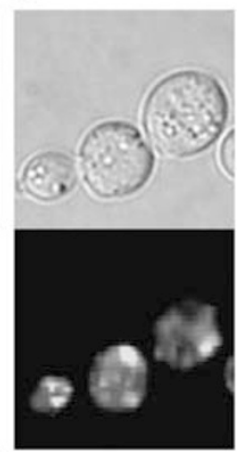

Figure 4 Effects of PMB, SAM and MON, and the combination of PMB and either SAM or MON on the vacuole morphology of Saccharomyces cerevisiae cells. After FM4-64 fluorescent dye treatment, cells $\left(10^{7} \mathrm{ml}^{-1}\right)$ were incubated in YPD medium with none (a), $50 \mu \mathrm{g} \mathrm{ml} l^{-1} \mathrm{PMB}(\mathbf{b}), 200 \mu \mathrm{g} \mathrm{ml} \mathrm{I}^{-1} \mathrm{PMB}$ (c),

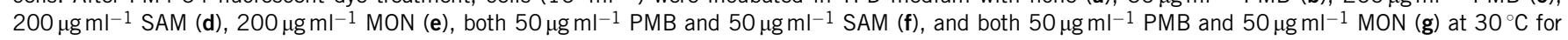
$120 \mathrm{~min}$. Cells were observed under the bright field microscope (top) and a fluorescence microscope (bottom). 
a

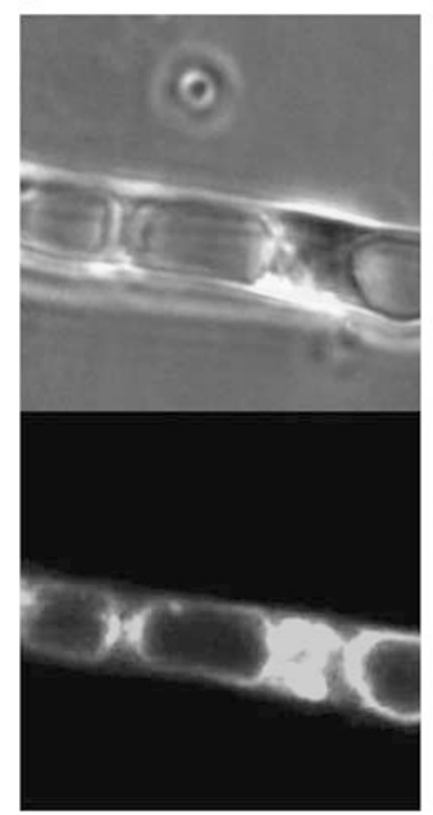

b

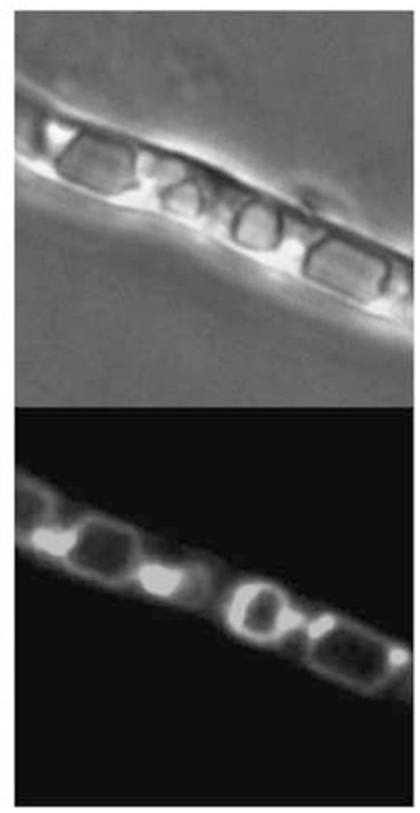

C

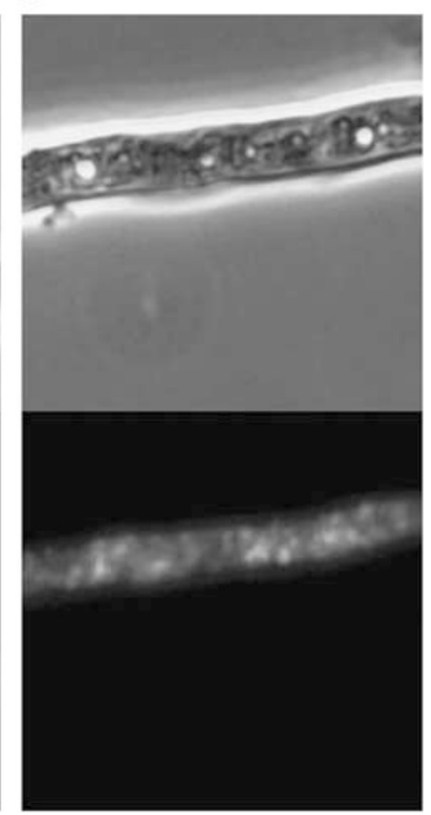

Figure 5 Effects of PMB in the absence and the presence of MON on vacuole morphology of Aspergillus niger cells. After FM4-64 fluorescent dye treatment,

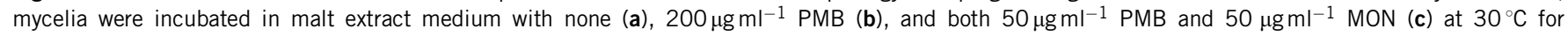
$120 \mathrm{~min}$. Mycelia were observed under a phase-contrast microscope (top) and a fluorescence microscope (bottom).

observation of $S$. cerevisiae and A. niger cells. The vacuoles were observed with swollen spherical architectures in untreated cells of S. cerevisiae and those treated with PMB alone at $50 \mu \mathrm{g} \mathrm{ml}^{-1}$ (Figures $4 \mathrm{a}$ and $\mathrm{b}$ ). In agreement with our earlier finding, the yeast vacuoles were observed as small discrete dots in the cytoplasm, representing fragmentation or disruption of the membranous architecture of the organelle when cells were treated with PMB at $200 \mu \mathrm{g} \mathrm{ml}^{-1}$ (Figure 4c). Although SAM and MON induced none of alterations in the vacuole morphology at $200 \mu \mathrm{g} \mathrm{ml}^{-1}$, the presence of each ionophore at $50 \mu \mathrm{g} \mathrm{ml}^{-1}$ made the organelles susceptible to the disruptive action of PMB at $50 \mu \mathrm{g} \mathrm{ml}^{-1}$ in a similar manner (Figures $4 \mathrm{e}-\mathrm{g}$ ). The vacuoles of $A$. niger were observed with the oval to rectangular architectures in the filamentous chains of untreated cells as well as those treated with PMB alone at $200 \mu \mathrm{g} \mathrm{ml}^{-1}$, as shown in Figure 5 . The organelles lost the original morphology, being visible with faintly stained amorphous images upon PMB treatment at $50 \mu \mathrm{g} \mathrm{ml}^{-1}$ in combination with MON at $50 \mu \mathrm{g} \mathrm{ml}^{-1}$.

\section{Effects of SAM and MON on cellular uptake of PMB}

Allicin is a sulfur-containing compound, and increases plasma membrane oxidation status in S. cerevisiae cells to a limited extent through its inhibitory effect on cell surface localization of alkyl hydroperoxide reductase 1 (ref. 24). The yeast plasma membrane was thus made permeable to intracellular $\mathrm{K}^{+}$, but was prevented from further structural modifications leading to irreversible disruption, possibly with the aid of unknown activity of allicin. This is supported by the fact that the yeast cells are absolutely viable even if the cell growth can be fully repressed upon allicin treatment at a high concentration. ${ }^{24}$ SAM stimulates alkali cation transport and thus inhibits oxidative phosphorylation in the rat liver mitochondria. ${ }^{25}$ An impairment of mitochondrial electron transport function can be a cause of mitochondrial reactive oxygen species generation, and this intracellular oxidative stress may consequently enhance plasma membrane

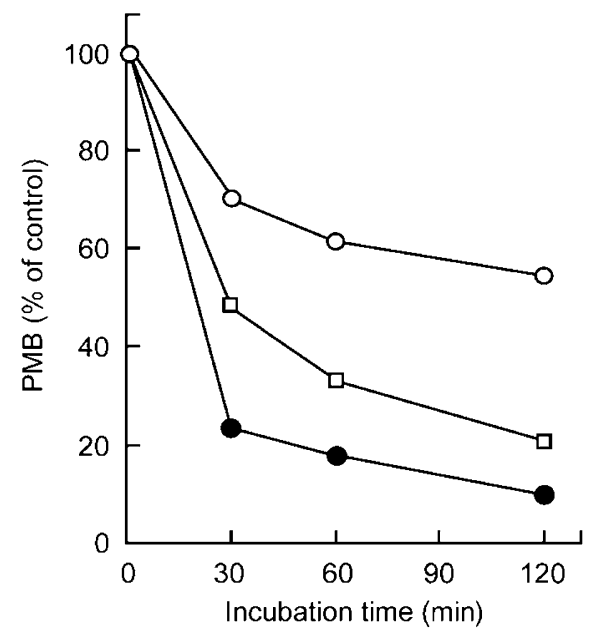

Figure 6 Effects of SAM and MON on the cellular uptake of PMB in Saccharomyces cerevisiae cells. Cells $\left(10^{7}\right.$ cells $\left.^{-1}\right)$ were incubated in YPD medium with $100 \mu \mathrm{gml}^{-1}$ PMB $(O)$, both $100 \mu \mathrm{g} \mathrm{ml}^{-1} \mathrm{PMB}$ and $100 \mu \mathrm{g} \mathrm{ml}^{-1} \mathrm{SAM}(\bullet)$, and both $100 \mu \mathrm{g} \mathrm{ml}^{-1} \mathrm{PMB}$ and $100 \mu \mathrm{g} \mathrm{ml}^{-1} \mathrm{MON}$ ( $\square$ ) at $30^{\circ} \mathrm{C}$.

phospholipid peroxidation, as in the case with allicin-dependent cellular uptake of PMB. ${ }^{26,27}$ The effects of SAM and MON on the cellular uptake of $\mathrm{PMB}$ were therefore examined by measuring the extracellular concentration of PMB by HPLC analysis. As shown in Figure 6, PMB indeed disappeared from the supernatant when cells were incubated with the antibiotic alone, but the rate of its disappearance was reduced along with the time of incubation. This may be due to its penetration into the plasma membrane, but not into the cytoplasm. The presence of either SAM or MON apparently contributed to elevation in the rate of PMB uptake by cells, possibly 
a

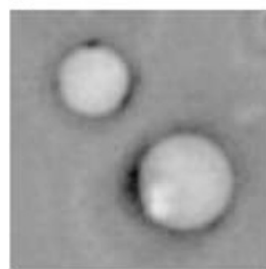

b

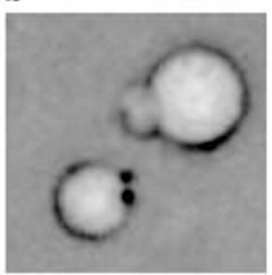

c

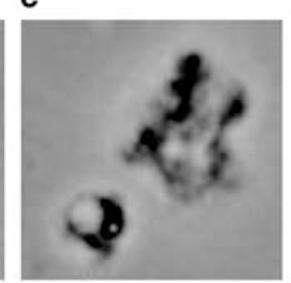

d

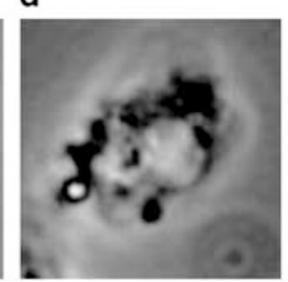

e

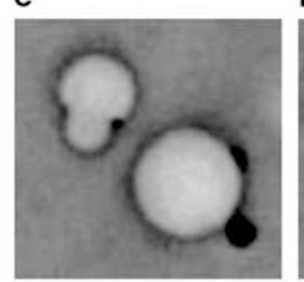

f

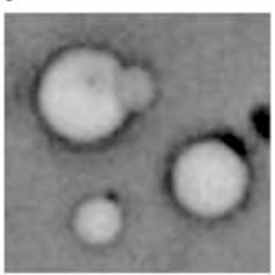

Figure 7 Disruptive effects of PMB on the isolated vacuoles in the absence and the presence of either SAM or MON. The isolated vacuoles were incubated with PMB at 6.25 (a), 12.5 (b), 25 (c), and $50 \mu \mathrm{g} \mathrm{ml} \mathrm{l}^{-1}$ (d) at $30^{\circ} \mathrm{C}$ for $120 \mathrm{~min}$. The organelles were also incubated with $12.5 \mu \mathrm{g} \mathrm{ml} \mathrm{l}^{-1} \mathrm{PMB}$ in the presence of either $200 \mu \mathrm{gll}^{-1} \mathrm{SAM}$ (e) or $200 \mu \mathrm{g} \mathrm{m} l^{-1} \mathrm{MON}$ (f) at $30^{\circ} \mathrm{C}$ for $120 \mathrm{~min}$.

representing the corresponding accumulation of this antibiotic inside the cells.

We next confirmed whether SAM or MON increases the oxidation status of plasma membrane phospholipid using t-butyl hydroperoxide as a positive control that can also increase the rate of cellular uptake of PMB. ${ }^{6}$ The extent of phospholipid peroxidation was kept unchanged with or without each ionophore at $200 \mu \mathrm{g} \mathrm{ml}^{-1}$ in comparison with its increase (1.6-fold of untreated control) in $t$-butyl hydroperoxide-treated cells. These findings highly support the idea that the loss of energy barrier for transmembrane transport of monovalent cations can be a cause of enhanced incorporation of larger cationic compounds such as PMB across the fungal plasma membrane.

\section{Direct disruptive action of PMB on the isolated vacuoles}

The results obtained above suggest the possibility that PMB can directly interact with the vacuole when this cationic cyclic peptide is incorporated into the cytoplasm of fungal cells. To confirm this possibility, the organelles were isolated from $S$. cerevisiae cells and were incubated with $\mathrm{PMB}$ in the absence and the presence of each ionophore. As shown in Figure 7, the isolated vacuoles were observed as spherical membrane-enclosed architectures with various sizes and were subjected to drastic disruptive damages after incubation with PMB alone. The minimum concentration of PMB effective for its complete disruption was $25 \mu \mathrm{g} \mathrm{ml}^{-1}$. The isolated vacuoles were not disrupted with $\mathrm{PMB}$ at $12.5 \mu \mathrm{g} \mathrm{m}^{-1}$ even if the assay mixture was further supplemented with each ionophore at $200 \mu \mathrm{g} \mathrm{ml}^{-1}$. This agrees well with the above idea that these ionophores can facilitate cellular uptake of PMB in favor of its direct action on this organelle inside the cells.

Vacuoles perform various functions, such as $\mathrm{pH}$ and ion homeostasis, osmoregulation, and volume regulation, by undergoing the organized membrane fusion and fission. ${ }^{28}$ Fusion of the isolated vacuoles is provoked by ATP supplementation for activating various peripheral membrane proteins. PMB-induced morphological change of the organelle should be attributed to unorganized disintegration of phospholipid membrane, but not to in vitro induction of organized or systemic fission process of the organelle. The vacuolar membrane of $S$. cerevisiae is characterized by the lowest content of ergosterol among various subcellular membranous architectures including plasma membrane with the highest ergosterol content. ${ }^{29}$ Instead, inositolphosphorylceramide is highly enriched in the vacuolar membrane where phosphatidylcholine is detected as the major phospholipid component. ${ }^{30} \mathrm{PMB}$ may exhibit a disruptive effect on the fungal vacuole through its interaction with inositolphosphorylceramide embedded in the phosphatidylcholine membrane. This antibiotic may otherwise trigger the vacuolar membrane disintegration depending on its interaction with a peripheral protein critical for the biogenesis of this organelle. Our studies are currently in progress to clarify the mechanism underlying the vacuole disruption by PMB.

\section{ACKNOWLEDGEMENTS}

This work was supported in part by a Grant-in-Aid for Scientific Research (C) (No. 20580083) from Japan Society for the Promotion of Science.

1 Vaara, M. Analytical and preparative high-performance liquid chromatography of the papain-cleaved derivative of polymyxin B. J. Chromatogr. 441, 423-430 (1988).

2 Hancock, R. E. Peptide antibiotics. Lancet 349, 418-422 (1997).

3 Boguslawski, G. Effects of polymyxin B sulfate and polymyxin B nonapeptide on growth and permeability of the yeast Saccharomyces cerevisiae. Mol. Gen. Genet. 199, 401-405 (1985).

4 Moneib, N. A. In-vitro activity of commonly used antifungal agents in the presence of rifampin, polymyxin B and norfloxacin against Candida albicans. J. Chemother. 7, 525-529 (1995).

5 Schwartz, S. N., Medoff, G., Kobyashi, G. S., Kwan, C. N. \& Schlessinger, D. Antifungal properties of polymyxin $B$ and its potentiation of tetracycline as an antifungal agent. Antimicrob. Agents Chemother. 2, 36-46 (1972).

6 Ogita, A., Nagao, Y., Fujita, K. \& Tanaka, T. Amplification of vacuole-targeting fungicidal activity of antibacterial antibiotic polymyxin B by allicin, an allyl sulfur compound from garlic. J. Antibiot. 60, 511-518 (2007).

7 Ogita, A., Matsumoto, K., Fujita, K., Usuki, Y., Hatanaka, Y. \& Tanaka, T. Synergistic fungicidal activities of amphotericin $B$ and $N$-methyl- $N^{\prime \prime}$-dodecylguanidine: a constituent of polyol macrolide antibiotic niphimycin. J. Antibiot. 60, 27-35 (2007).

8 Nakayama, K., Yamaguchi, T., Doi, T., Usuki, Y., Taniguchi, M. \& Tanaka, T. Synergistic combination of direct plasma membrane damage and oxidative stress as a cause of antifungal activity of polyol macrolide antibiotic niphimycin. J. Biosci. Bioeng. 94, 207-211 (2002)

9 Usuki, Y., Matsumoto, K., Inoue, T., Yoshioka, K., lio, H. \& Tanaka, T. Structure-activity relationship studies on niphimycin, a guanidylpolyol macrolide antibiotic. Part 1: the role of the $N$-methyl- $N^{\prime \prime}$-alkylguanidinium moiety. Bioorg. Med. Chem. Lett. 16, 1553-1556 (2006).

10 Ogita, A., Fujita, K., Taniguchi, M. \& Tanaka, T. Enhancement of the fungicidal activity of amphotericin B by allicin, an allyl-sulfur compound from garlic, against the yeast Saccharomyces cerevisiae as a model system. Planta Med. 72, 1247-1250 (2006).

11 Lindsay, D. S. \& Blagburn, B. L. Antiprotozoan. Antiprotozoan drugs. In Veterinary Pharmacology and Therapeutics (ed Adams, H. R.) 969-983 (Iowa State University Press, Amsterdam, 1995).

12 Westley, J. W. Chemical transformations of polyether antibiotics. In Polyether Antibiotics: Naturally Occurring Acid lonophores Chemistry Vol 2 (ed Westley, J. W.) 51-87 (Marcel Dekker Inc., New York, 1983).

13 Haney, M. E. Jr. \& Hoehn, M. M. Monensin, a new biologically active compound. I. Discovery and isolation. Antimicrob. Agent Chemother. 7, 349-352 (1967).

14 Butaye, P., Devriese, L. A. \& Haesebrouck, F. Antimicrobial growth promoters used in animal feed: effects of less well known antibiotics on Gram-positive bacteria. Clinic Microbiol. Rev. 16, 175-188 (2003).

15 Takahashi, M., Shibata, M. \& Niki, E. Estimation of lipid peroxidation of live cells using a fluorescent probe, diphenyl-1-pyrenylphosphine. Free Radic. Biol. Med. 31, 164-174 (2001).

16 Ogita, A., Fujita, K., Taniguchi, M. \& Tanaka, T. Dependence of synergistic fungicidal activity of $\mathrm{Cu}^{2+}$ and allicin, an allyl sulfur compound from garlic, on selective accumulation of the ion in the plasma membrane fraction via allicin-mediated phospholipid peroxidation. Planta Med. 72, 875-880 (2006). 
17 Conradt, B., Shaw, J., Vida, T., Emr, S. \& Wickner, W. In vitro reactions of vacuole inheritance in Saccharomyces cerevisiae. J. Cell Biol. 119, 1469-1479 (1992).

18 Ohsumi, Y. \& Anraku, Y. Active transport of basic amino acids driven by a proton motive force in vacuolar membrane vesicles of Saccharomyces cerevisiae. J. Biol. Chem. 256, 2079-2082 (1981).

19 Tabuchi, M. et al. Vacuolar protein sorting in fission yeast: cloning, biosynthesis, transport, and processing of carboxypeptidase $Y$ from Schizosaccharomyces pombe. J. Bacteriol. 179, 4179-4189 (1997).

20 Vida, T. A. \& Emr, S. D. A new vital stain for visualizing vacuolar membrane dynamics and endocytosis in yeast. J. Cell Biol. 128, 779-792 (1995).

21 Arnold, T. M., Forrest, G. N. \& Messember, K. J. Polymyxin antibiotics for Gramnegative infections. Am. J. Health Syst. Pharm. 64, 819-826 (2007).

22 Liu, C. \& Hermann, T. E. Characterization of ionomycin as a calcium ionophore. J. Biol. Chem. 253, 5892-5894 (1978).

23 Reed, P. W. \& Lardy, H. A. A23187: a divalent cation ionophore. J. Biol. Chem. 247, 6970-6977 (1972)

24 Ogita, A. et al. Synergistic fungicidal activity of $\mathrm{Cu}^{2+}$ and allicin, an allyl sulfur compound from garlic, and its relation to the role of alkyl hydroperoxide reductase 1 as a cell surface defense in Saccharomyces cerevisiae. Toxicology 215, 205-213 (2005).

25 Mitani, M., Yamanishi, T., Miyazaki, Y. \& Otake, N. Salinomycin effects on mitochondrial ion translocation and respiration. Antimicrob. Agents Chemother. 9, 655-660 (1976).

26 Machida, K., Tanaka, T., Fujita, K. \& Taniguchi, M. Farnesol-induced generation of reactive oxygen species via indirect inhibition of mitochondrial electron transport chain in the yeast Saccharomyces cerevisiae. J. Bacteriol. 180, 4460-4465 (1998).

27 Machida, K. \& Tanaka, T. Farnesol-induced generation of reactive oxygen species dependent on mitochondrial transmembrane potential hyperpolarization mediated by $\mathrm{F}_{0} \mathrm{~F}_{1}$-ATPase in yeast. FEBS Lett. 462, 108-112 (1999).

28 Wickner, W. Yeast vacuoles and membrane fusion pathways. EMBO J. 21, 1241-1247 (2002).

29 Zinser, E., Sperka-Gottlieb, C. D., Fasch, E. V., Kohlwein, S. D., Paltauf, F. \& Daum, G. Phospholipid synthesis and lipid composition of subcellular membranes in the unicellular eukaryote Saccharomyces cerevisiae. J. Bacteriol. 173, 2026-2034 (1991).

30 Hecktberger, P., Zinser, E., Saf, R., Hummel, K., Paltauf, F. \& Daum, G. Characterization, quantification, and subcellular localization of inositol-containing sphingolipids of the yeast, Saccharomyces cerevisiae. Eur. J. Biochem. 225, 641-649 (1994). 